\title{
Coarctation of the aorta: review of 362 operated patients. Long-term follow-up and assessment of prognostic variables
}

\author{
M. Koller, M. Rothlin and $\AA$. SenNing \\ Department of Internal Medicine, Department of Surgery, University Hospital of Zürich, Switzerland
}

KEY WORDS: Postoperative hypertension, residual coarctation, false aortic aneurysms.

362 patients operated upon for coarctation of the aorta from 1961-1980 were analyzed retrospectively. Age at operation was $<2$ years in 74 (group A) and $\geqslant 2$ years in 288 patients (group B). Associated cardiovascular malformations were common, especially in group $A$ patients. Early mortality was $12.2 \%$ for group $A$ and $1.4 \%$ for group B patients. 336 patients were followed for 6 months to 21 years (mean 8.9 years). Late mortality was $0.8 \%$ per patient year. Associated cardiac defects and postoperative hypertension were responsible for most of the late deaths. Late reoperations were performed because of aortic valve disease, residual coarctation (with persistent hypertension) and aortic aneurysms at the site of anastomosis. The incidence of hypertension decreased from $82.5 \%$ preoperatively to $33.5 \%$ at discharge from the hospital. It decreased further during follow-up in patients operated $<10$ years of age, but remained constant in the older patients.

In conclusion, morbidity and mortality after operative repair of coarctation are determined mainly by ( 1 ) associated cardiac malformations, and (2) postoperative hypertension. Patients with isolated coarctation and postoperative normal blood pressure have an excellent prognosis. Patients operated upon from between 2-9 years of age carry the lowest risk for residual coarctation and late postoperative hypertension.

\section{Introduction}

In the natural history of coarctation two critical periods threaten health and life of the patients. Severe narrowing of the descending aorta and insufficient collateral circulation, particularly if there is an associated cardiac malformation, will lead to symptoms of left ventricular failure during the first year of life, in half of those patients even in the neonatal period. The majority of patients surviving the first year of life pass from an asymptomatic into the second critical phase which begins around age 15 and lasts through the third decade. More than $90 \%$ of the patients experience symptoms from their malformation by that time $\mathrm{e}^{[1]}$. Morbidity and mortality are mainly determined by complications of systemic hypertension associated with the coarctation. Patients may suffer from ischaemic cerebrovascular disease, intracranial haemorrhage,

Submitted for publication on 2 September 1986 and in revised form 10 November 1986.

Address for correspondence: Matthias Koller, M.D., Department of Intemal Medicine, University Hospital of Zürich, $\mathrm{CH}-8091$ Zürich, Switzerland. myocardial infarction, congestive heart failure or aortic rupture. At the age of 50 years over $80 \%$ of untreated patients have already died ${ }^{[2]}$. There are very few reports of asymptomatic elderly patients with coarctation ${ }^{[3]}$.

Operative repair of coarctation has largely improved survival. However, even in patients without an associated cardiovascular malformation, morbidity and mortality remain elevated compared to controls ${ }^{[4]}$. Postoperative persisting hypertension is thought to represent the main risk factor. Therefore, many reports have addressed the question of optimal timing of the operation in order to minimize the incidence of postoperative hypertension ${ }^{[1,5-11]}$. Although most authors agree that elective repair of coarctation should not be performed in infancy because of the risk of residual stenosis later in life, there is no agreement about how long the operation may be delayed in asymptomatic patients. In the literature, upper age limits vary from $6^{[1,7,8,10]}$ to 25 years ${ }^{[6]}$.

This study reports the pre- and postoperative findings as well as the long-term follow-up of all 362 patients operated upon for coarctation at the University Hospital of Zürich between 1961-1980. 


\section{Methods}

The records of 362 patients operated upon for coarctation at the University Hospital of Zürich over a 20 year period from 1961 to 1980 were reviewed. Special attention was focused at preoperative findings, the surgical technique, early postoperative as well as late follow-up of the patients. A questionnaire was sent to the patients in 1983. They were contacted by telephone or through their private physician if they did not respond spontaneously. Questions included actual blood pressure (measured by a physician), hospitalizations, complications such as cerebrovascular and coronary artery disease, lower leg weakness or parasthesia, cardiac symptoms (according to the NYHA classification), actual medication and death. In those patients who could not be contacted in 1983, records of previous ambulatory examinations, which had been sent to the documentation centre of our hospital, were reviewed.

Patients were divided into two groups according to their age at operation, group $\mathrm{A}:<2$ years and group $B \geqslant 2$ years.

\section{DEFINITION OF HYPERTENSION}

In patients over age 18 years hypertension was defined as blood pressure values $>140 / 90 \mathrm{mmHg}$. This blood pressure limit (instead of a higher value, e.g. $>160 / 95 \mathrm{mmHg}$ ) is based on our results obtained in the late postoperative examination of a limited number of patients ${ }^{[12]}$. The significance of a resting blood pressure between $140 / 90$ and $160 /$ $95 \mathrm{mmHg}$ is derived from the observation that 6 of 7 $(85.7 \%)$ patients demonstrate hypertension with exercise. Hypertension with exercise was found significantly more frequent in patients with a resting blood pressure $>140 / 90 \mathrm{mmHg}$ ( 8 of 9 patients) compared to those $\leqslant 140 / 90$ ( 3 of 12 patients, $\chi^{2}=$ $8.416, P<0.01$ ). Hypertension was called moderate if the diastolic blood pressure exceeded $105 \mathrm{mmHg}$ and severe if it exceeded $115 \mathrm{mmHg}$. In patients below 18 years of age hypertension was diagnosed if the systolic or diastolic blood pressure exceeded the 95th percentile for their age group according to the Report of the National Heart, Lung and Blood Institutes Task Force on Blood Pressure Control in Children $^{[13]}$.

Patients with normal blood pressure values were considered hypertensive if they received antihypertensive drugs. Paradoxical hypertension is defined as a systolic and/or diastolic early postoperative blood pressure which exceeds the preoperative blood pressure by at least $20 \mathrm{mmHg}$.

\section{BLOOD PRESSURE DETERMINATIONS}

Preoperative measurements: Average blood pressure values are indicated where several measurements were available. Postoperatively, the patients stayed in the intensive care unit for 1 to 3 days. During this period multiple daily blood pressure determinations were made. In order to detect patients with paradoxical postoperative hypertension, the highest blood pressure measurements during those days (at least two sequential high blood pressure measurements not associated with postoperative pain) were registered. All patients had multiple blood pressure determinations through their postoperative course until their discharge from hospital. A first postoperative ambulatory examination was performed 6 months after the operation in one of the university hospitals. During late follow-up most patients were reexamined several times at the University Hospitals of Zürich, the University Children's Hospital of Zürich, at other hospitals in Switzerland or abroad, as well as by their private physician.

\section{STATISTICAL ANALYSIS}

The chi square test was employed for statistical analysis. $P<0.05$ was accepted for statistical significance.

\section{Results}

\section{PATIENT POPULATION}

From 1961 to 1980362 patients ( 244 males, 118 females), were operated upon for coarctation. The ages at operation ranged from a few days to 64 years. 74 patients were $<2$ years (group A), 288 patients $\geqslant 2$ years (group B). One hundred and forty-four patients were between 2-19 years and $144 \geqslant 20$ years old at operation. Out of the 74 patients of group A 30 were operated upon during the first month, 63 during the first year of life. Only 34 patients $(9.3 \%)$ were operated upon after 40 years of age. Figure 1 illustrates the number of patients according to their age at operation. The percentage of patients operated before age 2 years of age doubled from the first $(1961-1970)$ to the second 10 -year period $(1971-1980 ; 12.0 \%$ to $25.9 \%$ ) whereas that of patients $\geqslant 20$ years decreased from $56.3 \%$ to $30.9 \%$.

Of all 362 patients, 13 died in the first month after the operation. In 13 additional patients only the hospital record was available. In the remaining 336 patients the postoperative follow-up ranged from $0.5-21.0$ years resulting in a total observation 


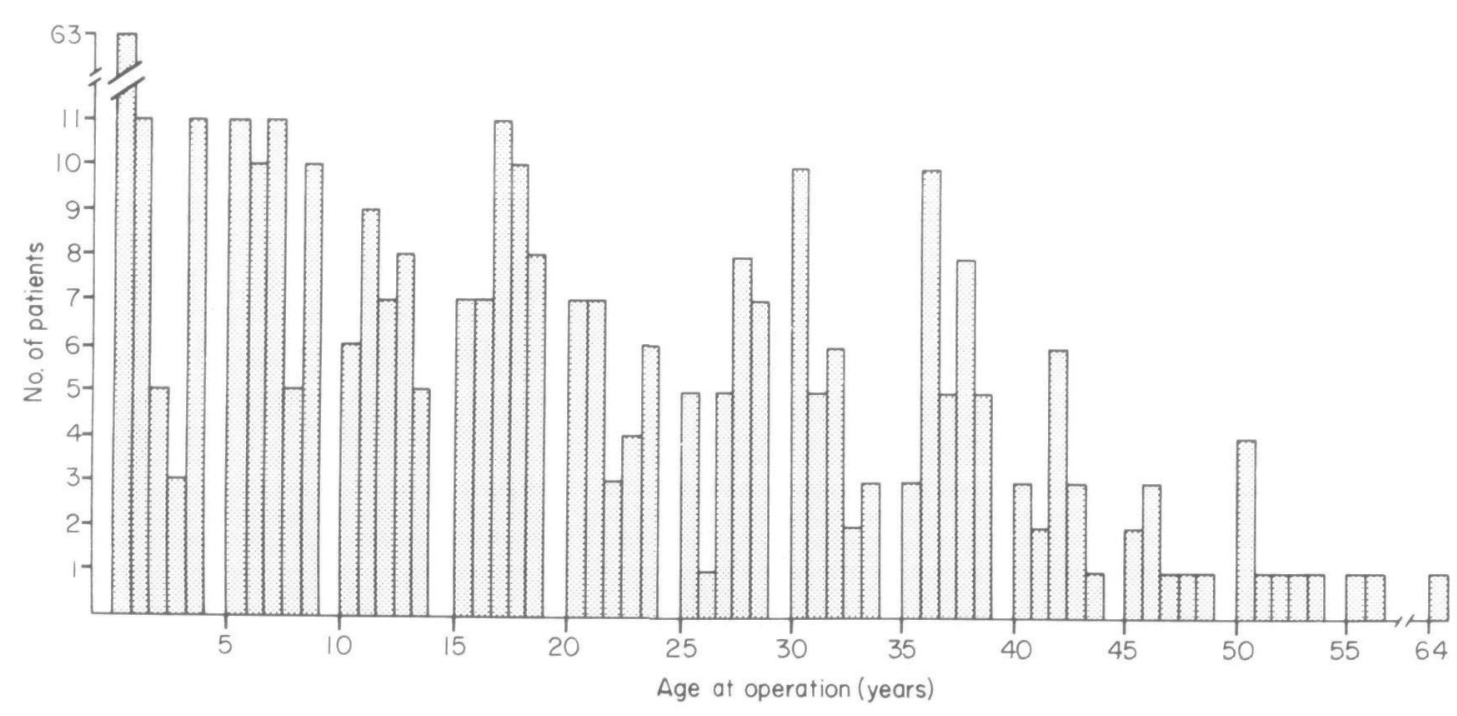

Figure 1 Age at operation of 362 patients operated for coarctation of the aorta 1961-1980.

period of 2983.5 years or 8.88 years per patient. Two hundred and sixty-five of the 336 patients $(78.9 \%)$ could be traced to the end of the observation period (1983) or to their death. Twenty-four patients died, 181 responded to the questionnaire and 60 were contacted by telephone directly or through their private physician. Postoperative follow-up ranged from 2.3-21.0 (mean $10 \cdot 4$ ) years. The remaining 71 patients could not be contacted in 1983. Documented follow-up in these patients varies between $0 \cdot 5-17 \cdot 8$ (mean 4.5 ) years.

\section{OPERATIVE PROCEDURES (TABLE 1 )}

In 296 patients $(81.8 \%)$ resection and end-toend-anastomosis was performed. Fifty-five $(15 \cdot 2 \%)$ needed graft material for the reconstruction of the descending aorta. In 21 patients, mainly babies, a plastic procedure (subclavian flap operation) was performed.

\section{ASSOCIATED CARDIOVASCULAR MALFORMATIONS \\ (TABLE 2 AND 3)}

The high frequency of associated cardiovascular defects in patients of group $A$ is evident. The leading malformation of these young patients were persistent ductus arteriosus (in 64.9\%), ventricular septal defect (in $33.8 \%$ ) and atrial septal defect (in $27.0 \%$ ). All persistent ductus arteriosi were ligated concomitantly with the operation of the coarctation. In 21 patients of group A with malformations complicated by pulmonary hypertension, a pulmonary banding procedure was performed together with

\section{Table I Operative procedures}

Resection, end-to-end-anastomosis

Resection, graft-interposition

Plastic repair

Resection, end-to-end-anastomosis, graft-patch

Total

the coarctation operation (ventricular septal defect 9 , ventricular and atrial septal defect 6 , atrial septal defect 1 , transposition of the great arteries 4, double outlet right ventricle with ventricular septal defect 1). A bicuspid aortic valve, the most common anomaly, was found in 94 of all patients $(26.0 \%)$, but only 40 of these had aortic valve dysfunction (regurgitation, stenosis or both); in 9 patients an aortic valve operation had to be performed simultaneously with the repair of coarctation. Mitral valve disease required operative correction only in 4 of 20 patients.

\section{MORTALITY}

\section{Operative mortality}

13 patients died in the operating room or during the first postoperative month. Nine of these patients were operated upon in their first year of life and all of them had severe associated cardiovascular malformations (5 ventricular septal defects, 2 hypoplastic left ventricles, 1 atrial septal defect, 1 mitral stenosis with associated pneumonia). Among 
Table 2 Associated cardio-vascular malformations

\begin{tabular}{ccc} 
& \multicolumn{2}{c}{ Group and patients age at operation } \\
\cline { 2 - 3 } Total & $\begin{array}{ll}\text { Group A } \\
<2 \text { years } \\
(N=74)\end{array}$ & $\begin{array}{l}\text { Group B } \\
\end{array}$ \\
& $(N=288)$
\end{tabular}

Bicuspid aortic valve

(a) Accidental finding

94

(b) Aortic stenosis

(c) Aortic regurgitation

(d) Combined defect

\begin{tabular}{rrr} 
& 12 & 42 \\
& 1 & 6 \\
4 & 2 & 4 \\
9 & 0 & 27 \\
5 & 0 & 4 \\
15 & 3 & 6 \\
71 & 1 & 4 \\
35 & 2 & 13 \\
26 & 48 & 23 \\
5 & 25 & 10 \\
6 & 20 & 6 \\
\hline & 5 & 0
\end{tabular}

2. Hypoplasia of the aortic arch

Anomalous pulmonary venous connection, pulmonary stenosis, double outlet right ventricle, vena cava supenor sinistra persistens, sinus-venosus defect, hypoplastic left ventricle

Table 3 Concomitant operation of associated cardiovascular malformattons

Ligation of patent ductus arteriosus

Aortic valve operation (valve replacement, reconstruction)

Mitral valve operation (valve replacement, reconstruction, commissurotomy)

Atrioseptostomy (Rashkind)

Closure of ventricular septal defect

Closure of atrial septal defect

Resection of membranous subvalvular aortic stenosis

Closure of sinus venosus defect

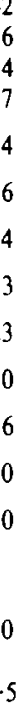




\section{Late Mortality}

Of the 336 patients who survived the first postoperative month and who could be followed for at least 6 months after the operation, 6 patients of group A and 18 patients of group B died, resulting in a late mortality of $24 / 2983.5$ patient years or $0.80 \%$ per patient year. Age at death was $2.6 \pm 1.9$ (SD) years for the 6 patients of group $A$ and $45 \cdot 2 \pm 14 \cdot 8$ (SD) years for the 18 patients of group B. Late mortality was strongly influenced by the age at operation, as can be seen in Fig. 2. It was lowest in patients between 2-19 years and highest in those $\geqslant 40$ years.

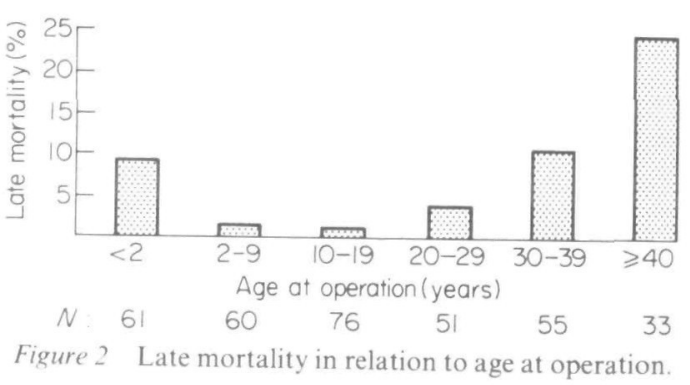

Five of the 6 patients of group A died because of severe associated cardiovascular defects (2 transposition of the great arteries plus ventricular septal defect, 1 ventricular and atrial septal defect, 1 ventricular septal defect, 1 atrial septal defect). One patient, a 4 year old girl, died in a car accident.

Ten of the deaths in group B were due to associated aortic valve disease (6 aortic regurgitation, 4 aortic stenosis). Two of these patients were children who died at the age of 9 (membraneous subvalvular aortic stenosis) and 15 (monocuspid aortic stenosis). Three patients died of other cardiovascular disease ( 2 myocardial infarction, 1 ruptured aneurysm of the ascending aorta), 3 of non-cardiovascular disease (1 lung cancer, 1 posthepatitic cirrhosis of the liver and 1 mountain climbing accident) and 2 of unknown cause. Postoperative hypertension was present in these last 2 patients as well as in the 3 with nonvalvular cardiovascular disease.

\section{COMPLICATIONS (INCLUDING REOPERATIONS)}

\section{Early complications}

Severe postoperative bleeding occurred in 5 patients, one of them died before reoperation was performed. Unilateral vocal cord paralysis was detected postoperatively in 2 patients. Two patients had to be reoperated early because of a dissection of the descending aorta and uncontrollable pleural effusion, respectively.

\section{Late complications}

Residual coarctation of the aorta, leading to reoperation was observed in 10 patients. 8 belonged to group A, the other 2 were 5 and 9 years old at operation. The incidence of reoperation because of residual coarctation was $13 \cdot 1 \%$ for the 61 patients of group A and $0.7 \%$ for the 275 patients of group B.

Reoperation because of an aneurysm of the descending thoracic aorta at the site of anastomosis was necessary in 5 patients. One patient was reoperated early, two months after the first operation. The other 4 were reoperated $13 \cdot 6,17,21$ and $21 \cdot 2$ years after the first operation which had been resection and Dacron graft-interposition (Table 1) in all 4 patients. Diagnosis was made by chance on routine chest X-ray (Fig. 3). Three patients with late aneurysms were successfully operated with an uneventful postoperative course. One patient died of left ventricular failure two days after an extended operation including aortic valve replacement and aortocoronary bypass grafting. In all 4 patients with Dacron grafts of the descending thoracic aorta, the first operation had been performed in the early 1960 s.

Myocardial infarction occurred in 3 patients, with fatal outcome in two. One patient had a transient ischaemic attack and another died of ruptured aneurysm of the ascending aorta. Postoperative hypertension was present in all these 5 patients. Subacute bacterial endocarditis developed two months after the operation in a patient with ventricular septal defect and in another 6 months after aortic valve replacement.

Reoperations because of associated cardiovascular defects. Thirteen aortic valve replacements were performed in 11 patients, because of aortic regurgitation in 8 , aortic stenosis in 3 and combined aortic valve lesion in 2 . Two patients received a prosthetic mitral valve. In 13 patients, a major congenital heart defect was corrected with a second operation: Ventricular septal defect ( 9 patients), transposition of the great arteries ( 3 operations in 2 patients), atrial septal defect (1 patient), anomalous pulmonary venous connection ( 1 patient).

\section{Postoperative hypertension}

Figure 4 illustrates the effect of operative correction of coarctation on systemic hypertension. Pre-operatively, $82.5 \%$ of all patients were hypertensive. Hypertension was moderate to severe in 


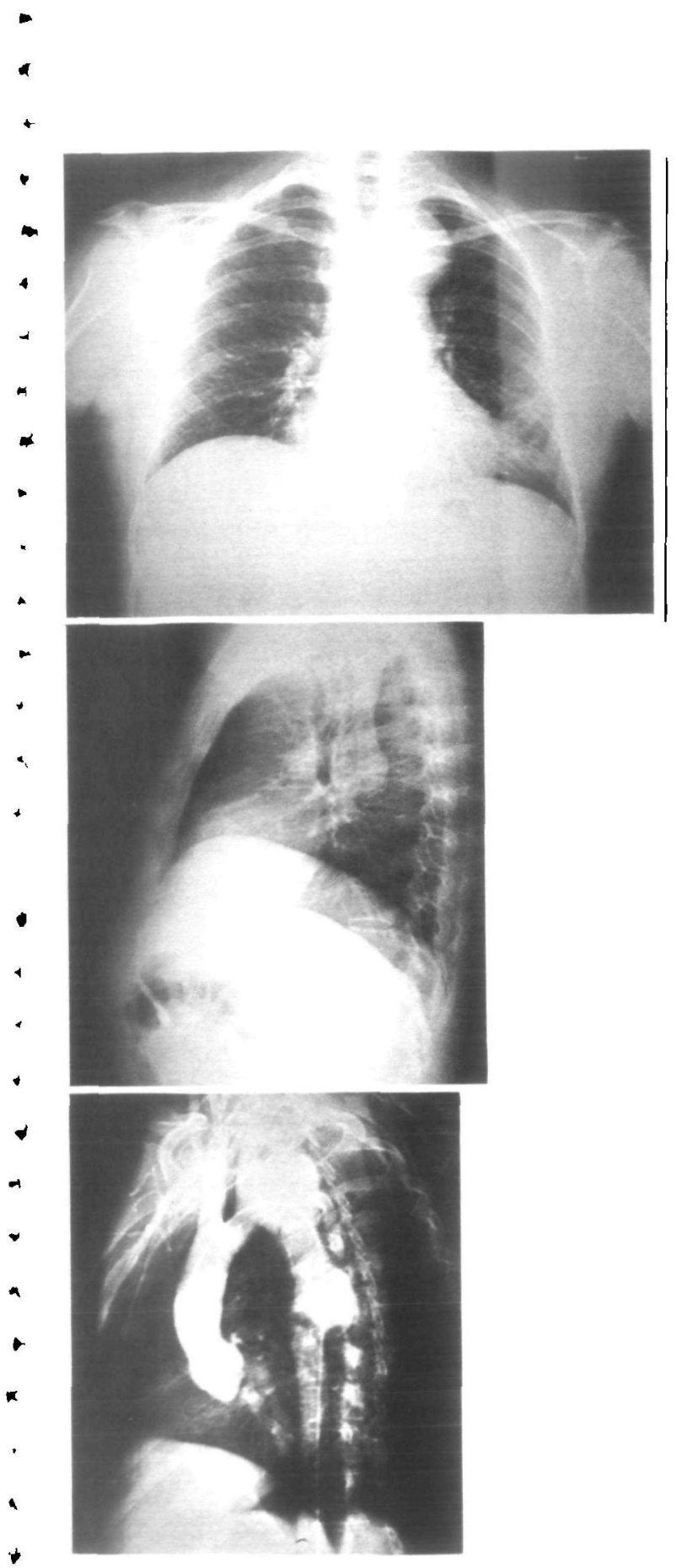

Figure 3 Chest X-ray (PA. and lat.) and aortic angiography (LAO projection) show a dumbbell-shaped aortic aneurysm in the isthmic region in a 37 year old man, 21 years after resection of coarctation of the aorta and Dacron graft implantation (silk sutures).

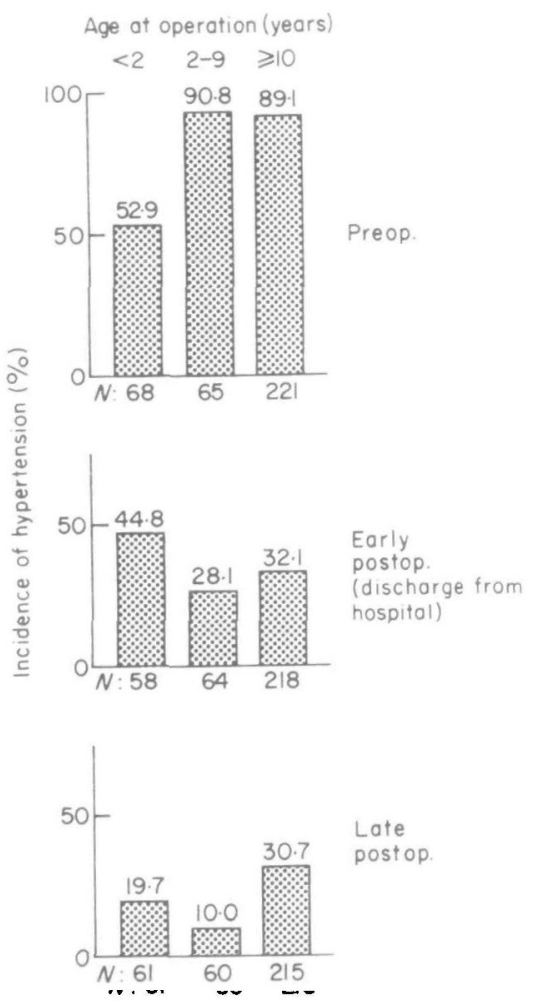

Figure 4 Pre- and postoperative incidence of hypertension in patients with coarctation of the aorta.

$19 \cdot 8 \%$. Due to the almost universally found cardiac insufficiency in patients of group $A$, the incidence of preoperative hypertension was significantly lower among the infants compared to patients of group B $(P<0 \cdot 001)$. At discharge from the hospital hypertension was only seen in $33.5 \%$ of all patients without a significant difference among the age groups. After the operation not only the overall incidence of hypertension had decreased but also the percentage of patients with moderate to severe hypertension has fell from $19 \cdot 8 \%$ to $0.6 \%$.

Paradoxical hypertension was found in $24.5 \%$ of the patients of all age groups. It did not correlate with preoperative or discharge blood pressure or with the age at operation, nor was it a predictor for late postoperative hypertension. No severe acute mesenteric arteritis occurred.

Of the 336 patients that could be followed for at least 6 months after the operation, $25.0 \%$ had late postoperative hypertension. Again, moderate to severe hypertension was found in only $0.6 \%$ of all patients. As can be seen in Fig. 4, the incidence of hypertension decreased further after discharge 
from the hospital in those operated before age 10 years, whereas it remained unchanged in the older patients. The incidence of hypertension in patients operated between 2-9 years $(10.0 \%)$ was significantly lower compared to all patients operated $\geqslant 10$ years $(30.7 \%, P<0.01)$ and even to the subgroup of patients operated upon between 10-19 years $(26.1 \%, P<0.02)$.

The results are similar if the 241 patients with a complete follow-up until the end of the study and an observation period between 2.3 and 21.0 years are considered. Here the incidence of hypertension was $19.9 \%$ for the whole group. Again, it was lower for patients operated upon at $<10$ years of age $(8.1 \%)$ compared to the older patients $(25.1 \%, P<0.01)$.

In 214 patients, blood pressure determinations from the upper and lower extremities were recorded in order to detect residual coarctation. In 80 patients residual coarctation, defined as a positive systolic pressure gradient between the upper and the lower extremities, was found. Postoperative residual coarctation was significantly more frequent in patients who had been operated upon as babies. Twenty-two of the 34 patients $(64.7 \%)$ operated upon before age 2 years showed a gradient whereas residual coarctation could be demonstrated in only 58 of the 181 patients $(32.0 \%)$ operated upon after 2 years of age $(P<0.001)$. There was, however, no significant difference in the incidence of systolic pressure gradients in patients operated between 2-9 years $(37.5 \%)$ compared to those operated $\geqslant 10$ years $(29.6 \%)$.

In patients with a pressure gradient, the incidence of hypertension was $46 \cdot 3 \%(37 / 80)$ as compared to $14.2 \%(19 / 134)$ in those without a pressure gradient $(P<0.001)$. Minor $(<25 \mathrm{mmHg})$ systolic pressure gradients were not associated with a higher incidence of postoperative hypertension. Of 63 patients with a systolic pressure gradient of $<25 \mathrm{mmHg} 14$ or $22.2 \%$ were hypertensive compared to 12 of 20 patients $(60 \%)$ with a gradient of $\geqslant 25 \mathrm{mmHg}$ $(P<0.01)$. Eight out of 10 patients with a pressure gradient $\geqslant 40 \mathrm{mmHg}$ were operated upon before age 2 years.

\section{ADDITIONAL. RESULTS FROM THE 181 QUESTIONNAIRES}

\section{Cardiac symptoms}

No restriction of physical capacity was indicated by 154 patients. Nineteen had to be classified in class II according to the NYHA, one in class III and none in class IV. Two patients suffered from severely debilitating multiple sclerosis (first symptoms of the disease in 1 patient several years before, in the other 4 years after the operation).

\section{Medication}

Twenty-six patients reported that they took one or more drugs regularly. Systemic hypertension was the most frequent indication ( 21 patients). The following drugs were used: diuretics (12), betablockers (9), other antihypertensive drugs (5), digoxin (4), nitrates (2), verapamil (1), phenprocoumon (1).

\section{Discussion}

Coarctation is an anomaly which affects twice as many boys as girls. Through the study period there was a tendency to operate on more babies and fewer patients $\geqslant 20$ years of age. Better operative technique and perioperative care for the very young patients as well as better awareness for the diagnosis of coarctation with earlier referral for operation during the second 10 years of the study period account for this finding.

Resection of the coarctation with end-to-end anastomosis was possible in the vast majority of our patients (Table 1). A plastic procedure (subclavian flap procedure) was performed in selected cases, mostly babies. Resection of the stenosis and graft interposition was necessary in those with elongated coarctation and in some older patients because of problems relating to insufficient mobilization of the aorta.

Our results clearly demonstrate that the prognosis of patients with coarctation is determined mainly by three factors: (1) clinically relevant associated cardiac malformations which, if present, are almost exclusively responsible for morbidity and mortality, (2) postoperative (remaining) hypertension accounting for a considerable amount of premature cardiovascular disease and death in middle-aged patients, and (3) postoperative complications at the site of operative repair of the aorta, namely residual coarctation and false aneurysms.

\section{ASSOCIATED CARDIAC MALFORMATIONS}

All studies on coarctation report on the frequent association with other cardiovascular malformations (Table 2). Patent ductus arteriosus and bicuspid aortic valves were by far the most frequent associated defects in our patients, confirming the results of previous series ${ }^{[7,9,14]}$.

Patent ductus arteriosus was always ligated together with the repair of the coarctation. It is

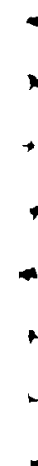

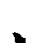

$\rightarrow$

$\checkmark$ 
located in the immediate proximity of the aortic isthmus and blood flow through the ductus is thought to play a crucial role in the pathogenesis of coarctation. A high ductal blood flow combined with an aortic arch malformation may lead to the development of the shell-shaped narrowing (coarctation) of the posterior aortic wall opposite to the ductus. In our patients a patent ductus arteriosus was the only associated malformation which did not bear an increased intra- and/or postoperative risk. This fact together with the close pathogenetic relationship suggest that a patent ductus in connection with coarctation should not be regarded as a separate defect but as a variant of coarctation. As pointed out by Shinebourne and Elseed ${ }^{[1]}$ the high ductal flow during the fetal period might also explain the development of coarctation in patients with associated intracardiac malformations. Cardiac lesions with a left-to-right shunt (VSD, ASD, transposition of the great arteries), with left ventricular outflow obstruction (aortic stenosis) or with left ventricular insufficiency (hypoplastic left ventricle, mitral valve disease) all display a high ductal flow.

The exact prevalence of an associated bicuspid aortic valve is not known. Although our results of $20.3 \%$ for group A and $27.4 \%$ for group B lie in the range of previous clinical studies which vary between $15 \%{ }^{[7]}$ and $39 \%^{[14]}$, the actual figure may well exceed $50 \%$. The clinical significance of bicuspid aortic valves cannot be completely derived from our data. Aortic valve replacement had to be performed in $14.9 \%$ of patients presenting with bicuspid valves, in 6 at the time of the repair of coarctation and in another 8 later during follow-up. 6 patients with bicuspid valves died. Aortic stenosis and regurgitation were equally represented.

Associated complex heart defects with haemodynamic significance were detected only in patients of group A. In fact, coarctation in these patients was often an accessory finding while the intracardiac malformation dominated the clinical picture. In several cases only a palliative procedure (pulmonary banding) was performed together with the repair of coarctation and the cardiac defect was definitively corrected when the child was 3-5 years old.

The cause of the observed deaths underlines the importance of associated congenital heart disease which account for most early and late deaths. However, there are distinct differences between group $\mathrm{A}$ and $\mathbf{B}$. In group $\mathbf{A}$, all fatal cases, except a girl who died in a car accident, were due to associated intracardiac, mostly complex defects. In group B, only one in two deaths occurred in patients with an additional malformation, mostly aortic valve disease.

\section{POSTOPERATIVE HYPERTENSION}

The hypertension associated with coarctation is considered one of the few surgically curable forms of hypertension. However, not every successful repair of coarctation normalizes the elevated blood pressure. Although differences in the definition of hypertension as well as in size and selection of age groups and time of follow-up make comparisons between studies rather difficult, some consistent results emerge from most investigations. First, not all patients respond favourably to the operation and second, the response rate is better for younger than for older patients ${ }^{[1,6-10,14]}$.

In evaluating the incidence of postoperative hypertension after repair of coarctation the definition of hypertension is important. In this report, blood pressure values exceeding $140 / 90 \mathrm{mmHg}$ are considered hypertensive in patients older than 18 years. The clinical relevance of this low range of hypertension ( $>140 / 90-160 / 95 \mathrm{mmHg}$ ) is reflected by results of exercise stress testing. Patients with low range hypertension demonstrate an incidence of stress hypertension of $85.7 \%$ compared to only $25.0 \%$ for the patients with a resting blood pressure $\leqslant 140 / 90 \mathrm{mmHg}^{[12]}$.

In almost $2 / 3$ of all patients who were hypertensive before the operation, blood pressure values returned to normal until discharge from the hospital (Fig. 4). Even more striking is the almost complete disappearance of moderate to severe forms of hypertension. During follow-up the incidence of hypertension declined further in patients operated upon before age 10 years while it remained constant in the older patients. The lowest incidence of late postoperative hypertension, $10.0 \%$, was found in patients operated between 2-9 years of age. This low figure corresponds to that obtained from a normal control population ${ }^{[16]}$. Therefore in this favourable age group, operation of coarctation cures preoperative hypertension and should normalize the increased risk for cardiovascular disease. However, the incidence of hypertension remains elevated in patients operated before 2 years of age and after 9 years of age. Residual coarctation explains the results of the very young patients. The association between the residual coarctation and hypertension is highly significant in our patients. Almost $2 / 3$ of patients of group $A$, but only $1 / 3$ of those of group B demonstrated a pressure gradient 
and severe gradients were found only in patients of group $\mathrm{A}$. The reason for the higher incidence of postoperative hypertension in patients operated at an age $\geqslant 10$ years remains speculative.

The clinical relevance of postoperative hypertension is demonstrated by the fact that all patients dying of cardiovascular disease not associated with congenital anomalies were hypertensive. Additional hypertensive patients suffered from non-fatal vascular disease.

\section{RESIDUAL COARCTATION, FALSE ANEUR YSMS}

Severe residual or recurrent coarctation which made a reoperation necessary, is a problem of the very young patient. The risk of being reoperated was $10.8 \%$ for patients of group A, $3.1 \%$ for those operated between 2-9 years and $0 \%$ for older patients.

The late development of false aneurysms of the descending aorta at the site of operation deserves mention. In all 4 patients with this complication the operation was performed in the early 1960s and included resection of coarctation and Dacron graft interposition. As described previously late failure of silk sutures may lead to the development of these aneurysms ${ }^{[7,17.18]}$. In all 4 patients diagnosis was made incidentally on a routine chest X-ray before spontaneous rupture had occurred. Angiography revealed typically a dumbbell-shaped aneurysm at the site of the graft (Fig. 3). It is not known how many patients who had received an aortic Dacron graft in the 1960 s developed such a dumbbellshaped aneurysm. Although these aneurysms remain asymptomatic for long periods as shown by our results, they may carry a considerable risk for aortic rupture. Therefore we suggest that patients with graft material, fixed by silk sutures, should have regular chest $X$-rays (every 3-5 years) in order to detect false aneurysms of the descending aorta.

\section{Conclusions}

Operative mortality as well as late morbidity and mortality are extremely low for patients with isolated coarctation who normalize their blood pressure after the operation. Based on our results an age between 2-9 years seems to be optimal both in achieving postoperative normotension and in avoiding residual coarctation. For practical reasons, operation is best performed at the age of $5-6$ years just before the child enters primary school.
In patients with postoperative hypertension residual coarctation should be sought. Our results suggest that a systolic pressure gradient between the upper and lower extremities of $\geqslant 30 \mathrm{mmHg}$ is relevant to hypertension and therefore is an indication for reoperation. Patients with lower or no pressure gradient have to be treated with antihypertensive drugs even if only borderline hypertension is found. Normalization of postoperative hypertension is expected to substantially decrease the incidence of cardiovascular disease.

In babies with complex cardiac anomalies, prognosis is dependent on the severity of those malformations and not on the coarctation. During late follow-up asymptomatic valvular heart disease, mainly bicuspid aortic valve regurgitation and stenosis, may become symptomatic. Therefore, in every patient preoperative diagnosis should include an accurate status of the aortic and mitral valve. The presence of valvular anomalies requires regular examinations.

We thank F. Real, Pediatric Cardiology, Unuversity Children's Hospital, Zürich, for kindly providing the medical records of the pediatric patients, and Mrs E. Bauer who takes care of the documentation of all patients operated for cardiovascular disease and was of great help in the correspondence with the patients, and Mrs M. Salman very kindly for the preparation of the manuscript.

\section{References}

[1] Karnell J. Coarctation of the aorta. Circulation 1968, 37, 38; Suppl V: V-35-44.

[2] Campbell $M$. Natural history of coarctation of the aorta. Br Heart J 1970; 32: 633-40.

[3] Haldane $\mathrm{JH}$. Coarctation of the aorta in an elderly man. Can Med Assoc J 1983; 128: 1298-9.

[4] Cokkinos DV, Leachman RD, Cooley DA. Increased mortality rate from coronary artery disease following operation for coarctation of the aorta at a late age. $J$ Thorac Cardiovasc Surg 1979; 77: 315-8.

[5] Schuster SR, Gross RE. Surgery for coarctation of the aorta. A review of 500 cases. J Thorac Cardiovasc Surg 1962; 43: 54-70.

[6] Maron BJ, Humphries JO, Rowe RD, Mellits ED. Prognosis of surgically corrected coarctation of the aorta. A 20-year postoperative appraisal. Circulation 1973; 47: 119-26.

[7] Pennington DG, Liberthson RR, Jacobs M, Scully H, Goldblatt A, Daggett WM. Critical review of experience with surgical repair of coarctation of the aorta. J Thorac Cardiovasc Surg 1979; 77: 217-29.

[8] Nanton MA, Olley PM. Residual hypertension of the coarctectomy in children. Am J Cardiol 1976; 37: 769-72.

[9] Clarkson PM, Nicholson MR, Barratt-Boyes BG, Neutze JM, Whitlock RM. Results after repair of coarctation of the aorta beyond infancy: a 10-28-year follow-up with particular reference to late systemic hypertension. Am J Cardiol 1983; 51: 1481-8. 
[10] Liberthson RR, Pennington DG, Jacobs ML, Daggett WM. Coarctation of the aorta: revrew of 234 patients and clarification of management problems. Am J Cardiol 1979; 43: 835-40.

[11] Lawrie GM, De Bakey ME, Morns GC, Crawford ES, Wagner WF, Glaeser DH. Late repair of coarctation of the descending thoracic aorta in 190 patients. Arch Surg 1981; 116: 1557-60.

[12] Koller $M$, Vetter $W$, Ziegler $W$. Contribution to pathogenesis of persistent hypertension after repair of coarctation of the aorta Eur J Clin Invest 1984; 14 (part II): 15 (Abstr).

[13] Standards for children's blood pressure (Task Force on Blood Pressure Control in Children). Pediatries 1977, 59 (Suppl): 802-3.
[14] Simon AB, Zloto AE. Coarctation of the aorta. Longtudinal assessment of operated patients Circulation 1974; 50: 456-64.

[15] Shinebourne EA, Elseed AM. Relation between fetal flow patterns, coarctation of the aorta, and pulmonary blood flow. Br Heart J 1974; 36: 492-8.

[16] Gutzwiller F, Schucan C, Junod B. Epidemılogssche und sozioökonomische Aspekte der grenzwertigen Hypertonie. Praxis 1982; 71: 5-10.

[17] Britt CI, Miller EM, Felder ME, Sirak HD. Comparative reaction of mersilene and silk sutures implanted within the heart. Ann Surg 1961; 153: 52-62.

[18] Gardner TJ, Brawley RK, Gott VL. Anastomotic false aneurysms. Surgery 1972; 72: 474-8. 